\title{
A Highly Toxic Cellular Prion Protein Induces a Novel, Nonapoptotic Form of Neuronal Death
}

\author{
Heather M. Christensen, ${ }^{*}$ Krikor Dikranian, ${ }^{\dagger}$ \\ Aimin Li, ${ }^{*}$ Kathleen C. Baysac, ${ }^{*}$ Ken C. Walls, ${ }^{\ddagger}$ \\ John W. OIney, ${ }^{\S}$ Kevin A. Roth, ${ }^{\ddagger}$ \\ and David A. Harris* \\ From the Departments of Cell Biology and Physiology, ${ }^{*}$ Anatomy \\ and Neurobiology, ${ }^{\dagger}$ and Psychiatry, ${ }^{\S}$ Washington University \\ School of Medicine, St. Louis, Missouri; and the Department of \\ Pathology, ${ }^{\ddagger}$ University of Alabama, Birmingham, Alabama
}

Several different deletions within the N-terminal tail of the prion protein (PrP) induce massive neuronal death when expressed in transgenic mice. This toxicity is dose-dependently suppressed by coexpression of full-length PrP, suggesting that it results from subversion of a normal physiological activity of cellular PrP. We performed a combined biochemical and morphological analysis of $\operatorname{Tg}(\Delta \mathrm{CR})$ mice, which express PrP carrying a 21-aa deletion (residues 105-125) within a highly conserved region of the protein. Death of cerebellar granule neurons in $\operatorname{Tg}(\Delta C R)$ mice is not accompanied by activation of either caspase- 3 or caspase- 8 or by increased levels of the autophagy marker, LC3-II. In electron micrographs, degenerating granule neurons displayed a unique morphology characterized by heterogeneous condensation of the nuclear matrix without formation of discrete chromatin masses typical of neuronal apoptosis. Our data demonstrate that perturbations in PrP functional activity induce a novel, nonapoptotic, nonautophagic form of neuronal death whose morphological features are reminiscent of those associated with excitotoxic stress. (Am J Pathol 2010, 176:2695-2706; DOI: 10.2353/ajpath.2010.091007)

Mechanisms of neuronal death have been studied intensively to gain insight into the pathological processes associated with acute and chronic neurological illnesses. Prion diseases are fatal neurodegenerative disorders of humans and animals that are accompanied by conversion of the cellular prion protein $\left(\mathrm{PrP}^{\mathrm{C}}\right)$ into a conformationally altered isoform ( $\mathrm{PrP}^{\mathrm{Sc}}$ ) that is infectious in the absence of nucleic acid. ${ }^{1}$ Although the basic principles of prion propagation are understood, the mechanism by which abnormal forms of PrP cause neuronal death remains obscure. Membrane-anchored $\mathrm{PrP}^{\mathrm{C}}$ is required to transduce neurotoxic signals elicited by pathogenic forms of PrP, suggesting that a normal biological activity of $\mathrm{PrP}^{\mathrm{C}}$ may be altered during the disease process. ${ }^{2-5}$ However, the cellular pathways and molecular components involved in this mechanism have yet to be identified.

A window into the neurotoxic potential of PrP comes from transgenic mice that express PrP molecules carrying deletions within the unstructured $\mathrm{N}$-terminal half of the protein. It was originally reported that mice expressing $\operatorname{PrP} \Delta 32-121$ or $\Delta 32-134$ (collectively referred to as $\operatorname{PrP} \Delta \mathrm{N}$ ) spontaneously develop a neurodegenerative illness characterized by massive degeneration of cerebellar granule neurons (CGNs) and by white matter abnormalities. ${ }^{6,7}$ Remarkably, this phenotype was exhibited only in the absence of endogenous PrP, and introduction of even a single Prn-p allele encoding wild-type PrP was sufficient to completely prevent the disease. ${ }^{6}$

To further define the sequence determinants of neurotoxicity, we previously generated $\mathrm{Tg}(\Delta \mathrm{CR})$ transgenic mice expressing PrP with a smaller deletion (residues 105-125) within the highly conserved central region of the protein. ${ }^{8} \mathrm{Tg}(\Delta \mathrm{CR})$ mice die within the first week of life on the Prn- $p^{O / O}$ background, and supraphysiological (5X) expression of wild-type PrP is necessary to confer survival beyond 1 year. ${ }^{8}$ Like $\operatorname{Tg}(\operatorname{PrP} \Delta \mathrm{N})$ mice, $\operatorname{Tg}(\Delta \mathrm{CR})$ animals display dramatic degeneration of CGNs and vacuolation of white matter regions. ${ }^{8}$ Importantly, $\operatorname{PrP}(\Delta \mathrm{CR})$ is identical to $\mathrm{PrP}^{\mathrm{C}}$ in terms of its solubility, protease sensitivity, and localization in cultured cells. ${ }^{8,9}$ Thus, we hypothesize that deletion of critical residues in the central region of $\mathrm{PrP}^{\mathrm{C}}$ alters a physiological activity of the protein rather than converting it to a misfolded state. Other PrP

Supported by grants from the National Institutes of Health (HD 37100, to J.W.O.; NS035107 and NS057098, to K.A.R.; and NS052526 and NS040975, to D.A.H.). H.M.C. was supported by a predoctoral fellowship (NS04691003) from the National Institutes of Health.

Accepted for publication February 18, 2010

Address reprint requests to David A. Harris, M.D., Ph.D., at his current address: Department of Biochemistry, Boston University School of Medicine, 72 East Concord St., K225, Boston, MA 02118. E-mail: daharris@bu.edu. 
deletion mutants encompassing this region are likely to act via a similar mechanism. ${ }^{10}$

To categorize the type of neuronal death induced by deleted forms of PrP, we have performed a combined biochemical, histological, and ultrastructural analysis of the brains of $\mathrm{Tg}(\Delta \mathrm{CR})$ mice. We discovered that neuronal loss in these animals does not occur through either apoptosis or autophagy. By electron microscopy, we observed a novel morphology in degenerating CGNs that is reminiscent of certain forms of excitotoxic neuronal death. The same morphology was present in mice expressing PrP $\Delta 32-134$, suggesting that a common nonapoptotic mechanism may underlie the neurotoxic activity of PrP proteins lacking the critical central region. Our study has implications for understanding PrP-related cell death pathways, and it represents a starting point for designing therapeutic strategies.

\section{Materials and Methods}

\section{Mice}

$\operatorname{Tg}(\Delta \mathrm{CR})$ mice (A line) were previously described ${ }^{8}$ and were maintained on the Tga20 $0^{+/ 0} / P r n-p^{+/+}$background. $\mathrm{Tg}\left(\Delta \mathrm{CR}^{+/ 0}\right) / \operatorname{Prn}_{-} p^{+/ 0}$ and $\mathrm{Tg}\left(\Delta \mathrm{CR}^{+/ 0}\right) / \mathrm{Prn}^{-p^{+/+}}$mice were generated by breeding $\operatorname{Tg}\left(\Delta \mathrm{CR}^{+/ 0}\right) / \mathrm{Tga} 2 \mathrm{O}^{+/ 0} / \mathrm{Prn}-p^{+/+}$ mice with $P r n-p^{O / O}$ and wild-type CBA mice, respectively. $\operatorname{Tg}(\mathrm{F} 35)$ mice $^{6}$ were obtained from A. Aguzzi (University of Zurich, Zurich, Switzerland) and Prn- $p^{O / O}$ mice ${ }^{11}$ from C. Weissmann (The Scripps Research Institute, Jupiter, $\mathrm{FL})$. Lurcher (Grid2 ${ }^{\mathrm{Lc} /+}$ ) mice were obtained from The Jackson Laboratory (Bar Harbor, ME).

\section{Western Blots}

Western blots of $\mathrm{Tg}(\Delta \mathrm{CR})$ cerebellar homogenates were performed as described previously. ${ }^{12}$ Caspase-3 was detected with an antibody that selectively recognizes the cleaved form of caspase-3 (catalog number 9662; Cell Signaling Technology, Danvers, MA). Brain homogenates from neonatal mice after hypoxia-ischemia injury served as a positive control for cleaved caspase-3. ${ }^{13}$ Poly(ADPribose) polymerase (PARP)-1/2 in cerebellar homogenates was detected using a rabbit polyclonal antibody (sc-7150) from Santa Cruz Biotechnology (Santa Cruz, CA). As a control for PARP-1 cleavage, HeLa cells were treated with $2 \mu \mathrm{mol} / \mathrm{L}$ staurosporine (Sigma-Aldrich, St. Louis, MO) for 24 hours to induce apoptosis.

For LC3 Western blots, positive controls included lysates from C17.2 neural stem cells that were treated to induce autophagy with either $10 \mathrm{nmol} / \mathrm{L}$ bafilomycin A1 (Sigma-Aldrich) or $25 \mu \mathrm{mol} / \mathrm{L}$ chloroquine (SigmaAldrich) plus $100 \mu \mathrm{mol} / \mathrm{L}$ boc-aspartyl(O-methyl)-fluoromethylketone (MP Biomedicals, Aurora, $\mathrm{OH}$ ). The LC-3 antibody (Atg8) was purchased from Abgent (San Diego, CA).

\section{Caspase Activity Assays}

Mice were sacrificed at $\mathrm{P} 15$ or $\mathrm{P} 20$ by $\mathrm{CO}_{2}$ asphyxiation. Cerebella were removed and flash frozen in liquid nitrogen. Caspase-3 and caspase-8 activities were assayed colorimetrically using kits from Calbiochem (San Diego, CA). Cerebella were homogenized in the cell lysis buffer supplied with the assay kits and supplemented with protease inhibitors (Complete Mini EDTA-free Protease Inhibitor Mixture; Roche, Indianapolis, IN). Caspase activity was determined by measuring the absorbance at $415 \mathrm{~nm}$ of the cleaved colorimetric substrate every 5 minutes for 2 hours. Activity was expressed as picomoles $p$-nitroaniline released per min per $50 \mu \mathrm{g}$ of brain homogenate protein. Brain homogenates from neonatal mice subjected to hypoxia-ischemia injury served as a positive control for caspase-3 activity. ${ }^{13}$

\section{Terminal Deoxynucleotidyl Transferase- Mediated dUTP Nick-End Labeling and Caspase-3 Immunohistochemistry}

Mice were transcardially perfused with $4 \%$ paraformaldehyde, and terminal deoxynucleotidyl transferasemediated dUTP nick-end labeling (TUNEL) of paraffin sections was performed using the In Situ Cell Death Detection Kit, according to the manufacturer's directions (Roche Diagnostics, Indianapolis, IN). Caspase-3 immunostaining of vibratome sections was performed as previously described, ${ }^{14}$ using an antibody directed toward cleaved caspase-3 (catalog number 9662; Cell Signaling Technology).

\section{Electron Microscopy}

Mice were anesthetized and transcardially perfused with PBS containing 3000 units/L heparin followed by fixation with $1.5 \%$ glutaraldehyde (Acros Organics, Geel, Belgium) $/ 1 \%$ paraformaldehyde (Electron Microscopy Sciences, Hatfield, PA) in $0.1 \mathrm{M}$ sodium phosphate buffer $(\mathrm{pH}$ 7.35). After perfusion, brains were removed and stored in the same fixative at $4^{\circ} \mathrm{C}$ for at least 24 hours. The cerebella were sectioned sagittally into $\sim 1-\mathrm{mm}$ sections, postfixed overnight in osmium tetroxide (Electron Microscopy Sciences), dehydrated in graded ethanols, and embedded in Polybed 812 (Polysciences, Warrington, PA). Sections, $1-\mu \mathrm{m}$ thick, were cut at the midsagittal level, using glass knives (1/2 inch wide) and an MT-2B Sorvall ultramicrotome. This approach allows any given portion of the cerebellum to be evaluated by either light or electron microscopy. The sections were stained with methylene blue and azure II for evaluation by light microscopy. For electron microscopy, areas of special interest (lobes 5 and 6) were trimmed to a smaller size. Ultrathin sagittal sections were cut on a Reichert-Jung Ultracut Microtome, suspended over a formvar-coated slot grid ( $1 \times 2 \mathrm{~mm}$ opening), and stained with uranyl acetate and lead citrate. Slot grids were used because they permit a continuous viewing field $(1 \times 2 \mathrm{~mm})$ uninterrupted by grid mesh bars. Sections were viewed on a 
Zeiss 902 Electron Microscope and recorded with Kodak E.M. film.

\section{Results}

\section{Neuronal Death in $\mathrm{Tg}(\Delta \mathrm{CR})$ Mice Is Not Accompanied by Activation of Caspase-3}

Both intrinsic and extrinsic apoptotic pathways converge at the level of the executioner caspase, caspase-3. ${ }^{15}$ To investigate whether granule cell death in $\operatorname{Tg}(\Delta \mathrm{CR})$ mice is apoptotic, we therefore tested for the presence of the cleaved (active) form of caspase-3 in cerebellar samples using both biochemical and histological methods. For these studies, we used $\operatorname{Tg}(\Delta C R) / P r n-p^{+/ 0}$ mice, which express the $\Delta C R$ transgene along with one copy of the endogenous Prn- $p$ allele. In these animals, $\operatorname{Pr} P(\Delta C R)$ and endogenous PrP are expressed at comparable levels. ${ }^{8}$

First, cerebellar homogenates from $\mathrm{Tg}(\Delta \mathrm{CR}) / \mathrm{Prn}-\mathrm{p}^{+/ 0}$ and control mice were analyzed by probing Western blots with an antibody that specifically recognizes the cleaved form of caspase-3 (Figure 1A). As a positive control, cleaved caspase-3 was detected in hippocampal homogenates from neonatal mice subjected to hypoxia-ischemia, a treatment known to induce neuronal apoptosis $^{16,17}$ (Figure 1A, lane 2). In contrast, we did not detect cleaved caspase-3 in terminally ill Tg( $\Delta \mathrm{CR}) / P r n-p^{+/ 0}$ mice (Figure 1A, lane 3). As negative controls, we analyzed cerebellar homogenates from $\mathrm{Tg}(\Delta \mathrm{CR})$ mice that were rescued by fivefold overexpression of wild-type $\operatorname{PrP}(\operatorname{Tg}(\Delta \mathrm{CR}) /$ Tga20/Prn- $\left.p^{+/ O}\right)$ and from nontransgenic animals $\left(P m-p^{+/ O}\right)$, neither of which possessed detectable amounts of cleaved caspase-3 (Figure 1A, lanes 4 and 5). No alterations in the levels of the full-length procaspase- 3 were observed in any of the samples (data not shown).

Next, we performed enzymatic assays of $\mathrm{Tg}(\Delta \mathrm{CR})$ cerebellar homogenates to detect hydrolysis of the peptide substrate DEVD (Asp-Glu-Val-Asp), an activity that is primarily indicative of activated caspase-3 (Figure 1B). DEVDase activity was detected in control brain homogenates supplemented with recombinant caspase- 3 and in samples from neonatal mice after hypoxia-ischemia (Figure 1B, black bar). However, cerebellar homogenates from $\mathrm{Tg}(\Delta \mathrm{CR}) / \mathrm{Prn}-p^{+/ 0}$ mice at postnatal day 15 (P15) or postnatal day 20 (P20) did not possess any detectable DEVDase activity (Figure 1B, white bar and striped bar, respectively). DEVDase activity was also undetectable in rescued $\left(\mathrm{Tg}(\Delta \mathrm{CR}) / \mathrm{Tga} 2 \mathrm{O} / \mathrm{Prn}-\mathrm{p}^{+/ 0}\right)$ and nontransgenic $\left(P r n-P^{+/ 0}\right)$ negative control animals.

To further investigate whether caspase-3 is activated in $\mathrm{Tg}(\Delta \mathrm{CR})$ mice, we analyzed the cleavage state of the caspase-3 substrate, PARP-1 (Figure 1C). PARP-1 is a nuclear enzyme responsive to DNA damage that undergoes a characteristic cleavage by activated caspase-3 during apoptosis. ${ }^{18}$ As a positive control, PARP-1 cleavage was apparent in HeLa cells treated with staurosporine, as evidenced by an increase in the proportion of the 89-kDa fragment (Figure 1C, lane 2, white arrowhead). In contrast, we did not observe any change in the amount of the 89-kDa PARP-1 fragment in cerebellar homoge-
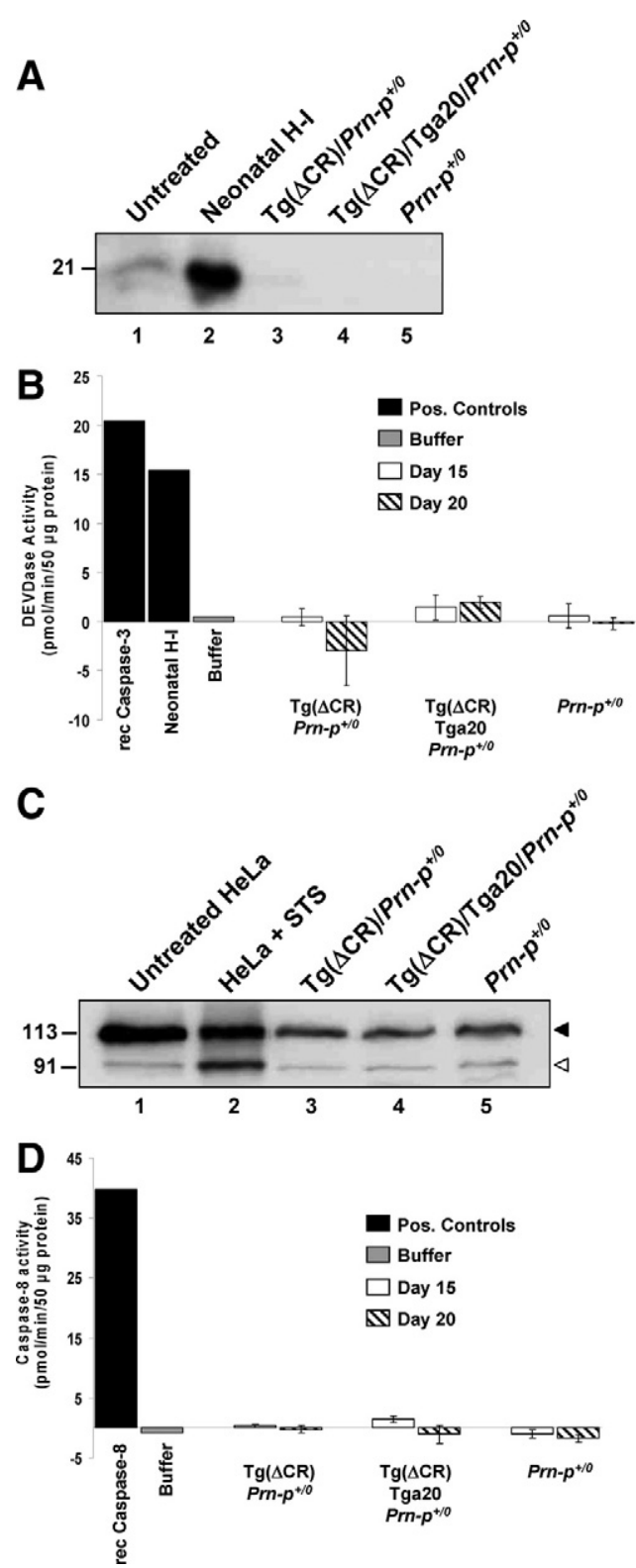

Figure 1. Neuronal death in $\operatorname{Tg}(\Delta \mathrm{CR})$ mice is not accompanied by activation of caspase-3 or caspase-8. A: Cerebellar homogenates from P25 $\operatorname{Tg}(\Delta \mathrm{CR})$ $P r n-p^{+/ 0}$ (lane 3), Tg( $\Delta$ CR $) / T g a 20 / P r n-p^{+/ 0}$ (lane 4), and $P r n-p^{+/ 0}$ (lane 5) mice were subjected to Western blotting using an antibody specific for the cleaved form of caspase-3. As positive controls, hippocampal homogenates from neonatal mice subjected to hypoxia-ischemia (lane 2) and age-matched control mice (lane 1) were also analyzed. B: Cerebellar homogenates from P15 (white bar) and P20 (striped bar) $\operatorname{Tg}(\Delta \mathrm{CR}) / \mathrm{Prn}_{-} \mathrm{p}^{+/ 0}$ mice were assayed for DEVDase-specific activity, primarily indicative of caspase-3. Hippocampal homogenates from neonatal mice subjected to hypoxia-ischemia, as well as normal cerebellar homogenates supplemented with recombinant caspase-3, served as positive controls (black bar). Data represent the mean \pm SEM for three mice from each genotype and age group. C: Cerebellar homogenates from P25 $\mathrm{Tg}(\Delta \mathrm{CR}) / \mathrm{Prn}_{-} \mathrm{p}^{+/ 0}$ (lane 3), $\mathrm{Tg}(\Delta \mathrm{CR}) / \mathrm{Tga} 20 / \mathrm{Prn}-$ $p^{+/ 0}$ (lane 4), and $P r n-p^{+/ 0}$ mice (lane 5) were subjected to Western blotting using an antibody to PARP-1 to assess caspase-3-induced cleavage of PARP-1. As positive controls, lysates from staurosporine-treated HeLa cells (lane 2) or untreated cells (lane 1) were also analyzed. Full-length PARP-1 and the $89-\mathrm{kDa}$ cleavage fragment are indicated by the black and white arrowheads, respectively. D: Cerebellar homogenates from P15 (white bar) and P20 (striped bar) $\mathrm{Tg}(\Delta \mathrm{CR}) / P r n-p^{+/ 0}$ mice were analyzed for caspase- 8 activity. Normal cerebellar homogenate supplemented with recombinant caspase- 8 served as a positive control (black bar). Data represent the mean \pm SEM for three mice from each genotype and age group. 

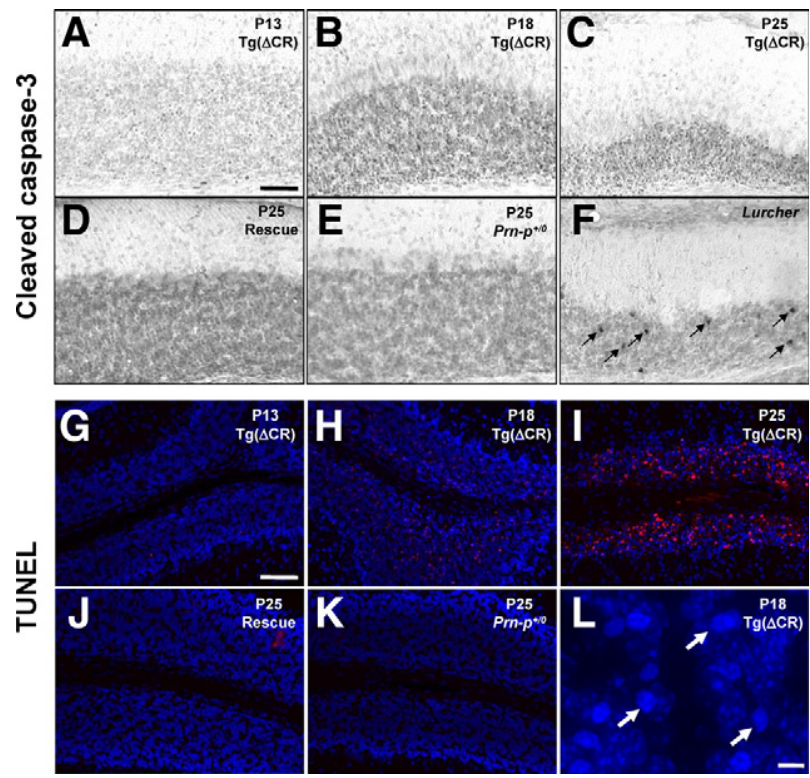

Figure 2. Time course of DNA fragmentation and caspase-3 activation in $\mathrm{Tg}(\Delta \mathrm{CR})$ mice. Cerebellar sections were prepared from $\mathrm{Tg}(\Delta \mathrm{CR}) / P r n-p^{+/ 0}$ mice at P13 (A and $\mathbf{G})$, P18 (B, H, and $\mathbf{L}$ ), and P25 (C and I); from $\operatorname{Tg}(\Delta \mathrm{CR}) / \mathrm{Tga} 20 / \mathrm{Prn}_{-} \mathrm{p}^{+/ 0}$ (rescue) mice $(\mathbf{D}$ and $\mathbf{J})$ and $P r n-p^{+/ 0}$ mice $(\mathbf{E}$ and K) at P25; and from Lurcher $\left(G r i d 2^{L C /+}\right)$ mice at P15 (F). Sections were subjected to immunostaining to reveal activated caspase-3 (A-F) or to TUNEL to reveal fragmented DNA $(\mathbf{G}-\mathbf{K})$. Numerous granule neurons containing activated caspase-3 are visible in the P15 Lurcher cerebellum (arrows in F). TUNEL-positive neurons are stained red, and nuclei are stained blue with $4^{\prime}, 6^{\prime}$-diamidino-2-phenylindole $(\mathbf{G}-\mathbf{K})$. $\mathbf{L}$ is a higher magnification image of a portion of the granule cell layer shown in $\mathbf{H}$. Arrows in $\mathbf{L}$ indicate pyknotic nuclei visible by $4^{\prime}, 6^{\prime}$-diamidino-2-phenylindole staining. Scale bars: $50 \mu \mathrm{m}$ $(\mathbf{A}-\mathbf{K}) ; 5 \mu \mathrm{m}(\mathbf{L})$

nates from $\mathrm{Tg}(\Delta \mathrm{CR}) / \mathrm{Prn}-p^{+/ 0}$ mice compared with control mice $\left(\mathrm{Tg}(\Delta \mathrm{CR}) / \mathrm{Tga} 20 / \mathrm{Prn}-\mathrm{p}^{+10}\right.$ and Prn- $\left.{ }^{+/ O}\right)$ (Figure $1 \mathrm{C}$, lanes $3-5)$.

In a final set of experiments, we used immunohistochemical techniques to visualize cleaved caspase-3 in brain sections from $\mathrm{Tg}(\Delta \mathrm{CR})$ mice. As a positive control for the staining reaction, granule neurons positive for cleaved caspase-3 were readily detected in the cerebella of Lurcher mice (Figure 2F, arrows). Granule neurons in Lurcher mice are known to undergo a Bax- and caspasedependent, apoptotic cell death secondary to autophagic degeneration of Purkinje cells. ${ }^{19}$ In contrast, we did not detect any neurons labeled for cleaved caspase-3 in the cerebella of $\mathrm{Tg}(\Delta \mathrm{CR}) / \mathrm{Prn}-p^{+/ 0}$ mice between 13 and 25 days of age (Figure 2, A-C). This age range spans a period of massive granule neuron degeneration in these animals, as evidenced by dramatic accumulation of TUNEL-positive cells (Figure 2, G-I), as well as shrinkage of the granule cell layer and appearance of pyknotic nuclei revealed by 4',6'-diamidino-2-phenylindole staining (Figure 2L, arrows). As expected, no cells positive for cleaved caspase-3 or TUNEL were observed in rescued or nontransgenic animals $\left(\mathrm{Tg}(\Delta \mathrm{CR}) / \mathrm{Tga} 20 / \mathrm{Prn}-\mathrm{p}^{+/ O}\right.$ and Prn- $p^{+/ 0}$ ) (Figure 2, D, E, J, and K). The lack of staining for cleaved caspase-3 in the face of massive, TUNELpositive cell loss argues that granule neurons in $\mathrm{Tg}(\Delta \mathrm{CR}) / \operatorname{Prn}-p^{+/ 0}$ mice are dying via a mechanism that results in DNA fragmentation without caspase activation. Both apoptotic and nonapoptotic (caspase-inde-

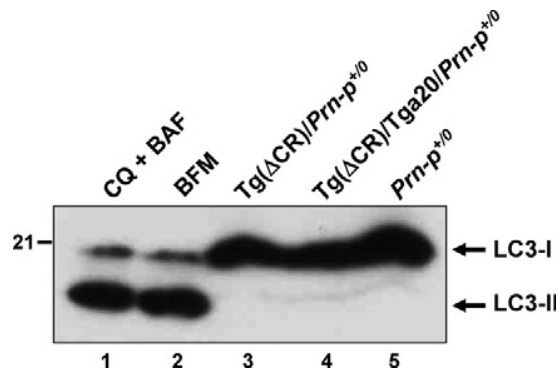

Figure 3. Neuronal death in $\operatorname{Pr} P(\Delta \mathrm{CR})$ mice is not accompanied by processing of the autophagic marker protein, LC3. Cerebellar homogenates from P25 $\operatorname{Tg}(\Delta \mathrm{CR}) / P r n-p^{+/ 0}$ (lane 3), $\operatorname{Tg}(\Delta \mathrm{CR}) / \mathrm{Tga} 20 / \mathrm{Prn}_{-} \mathrm{p}^{+/ 0}$ (lane 4), and Prn$p^{+/ 0}$ (lane 5) mice were subjected to Western blotting using an antibody to LC3. As positive controls, cell lysates from immortalized C17.2 neural precursor cells treated with a mixture of chloroquine (CQ) and boc-aspartyl $(O-$ methyl)-fluoromethylketone (BAF) (lane 1) or with bafilomycin A1 (BFM) (lane 2) were also analyzed. The positions of LC3-I (the precursor form) and LC3-II (the cleaved and lipidated form) are indicated.

pendent) cell death pathways are known to produce DNA fragmentation. ${ }^{20-22}$

\section{Neuronal Death in $\mathrm{Tg}(\Delta \mathrm{CR})$ Mice Is Not Accompanied by Activation of Caspase-8}

To confirm the lack of caspase activation in $\mathrm{Tg}(\Delta \mathrm{CR})$ mice, we performed enzymatic activity assays for caspase-8, which lies upstream of caspase-3 in the extrinsic (death receptor-mediated) apoptotic pathway. ${ }^{23}$ Cerebellar homogenates from $\mathrm{Tg}(\Delta C R) / \operatorname{Prn}-p^{+/ O}$ mice at 15 or 20 days of age, as well as from rescue and nontransgenic littermates did not contain detectable caspase- 8 activity (Figure 1D, white bar and striped bar). As a positive control, caspase-8 activity was detected in normal cerebellar homogenates supplemented with recombinant enzyme (Figure 1D, black bar). Thus, consistent with lack of caspase-3 activation, neuronal death in $\mathrm{Tg}(\Delta \mathrm{CR})$ mice does not involve activation of caspase-8 via the extrinsic apoptotic pathway.

\section{A Marker of Autophagy Is Not Elevated in $\mathrm{Tg}(\Delta \mathrm{CR})$ Brains}

Autophagy has been described both as a cell death mechanism and a survival response during periods of cellular stress. ${ }^{24}$ To test whether $\operatorname{PrP}(\Delta \mathrm{CR})$-induced cell death involves autophagy, we performed Western blots to detect microtubule-associated protein 1 light chain 3 (LC3), a marker of autophagosomes. On induction of autophagy, the LC3-I isoform undergoes cleavage and lipidation to produce a membrane-associated species, LC3-II, that has a slightly higher mobility on SDS-PAGE. ${ }^{25}$ We did not detect LC3-II in cerebellar homogenates from either $\operatorname{Tg}(\Delta C R) / P r n-p^{+10}$ or control mice (Figure 3, lanes 3-5), although this isoform was readily detectable in neural cells induced to undergo autophagy by treatment with chloroquine plus boc-aspartyl(O-methyl)-fluoromethylketone or with bafilomycin A1 (Figure 3, lanes 1 and 2). In addition, immunohistochemical studies failed to reveal any alteration in the subcellular distribution of LC3 in the cerebella of $\mathrm{Tg}(\Delta \mathrm{CR}) / \operatorname{Prn}_{-} \mathrm{p}^{+/ O}$ mice compared with con- 


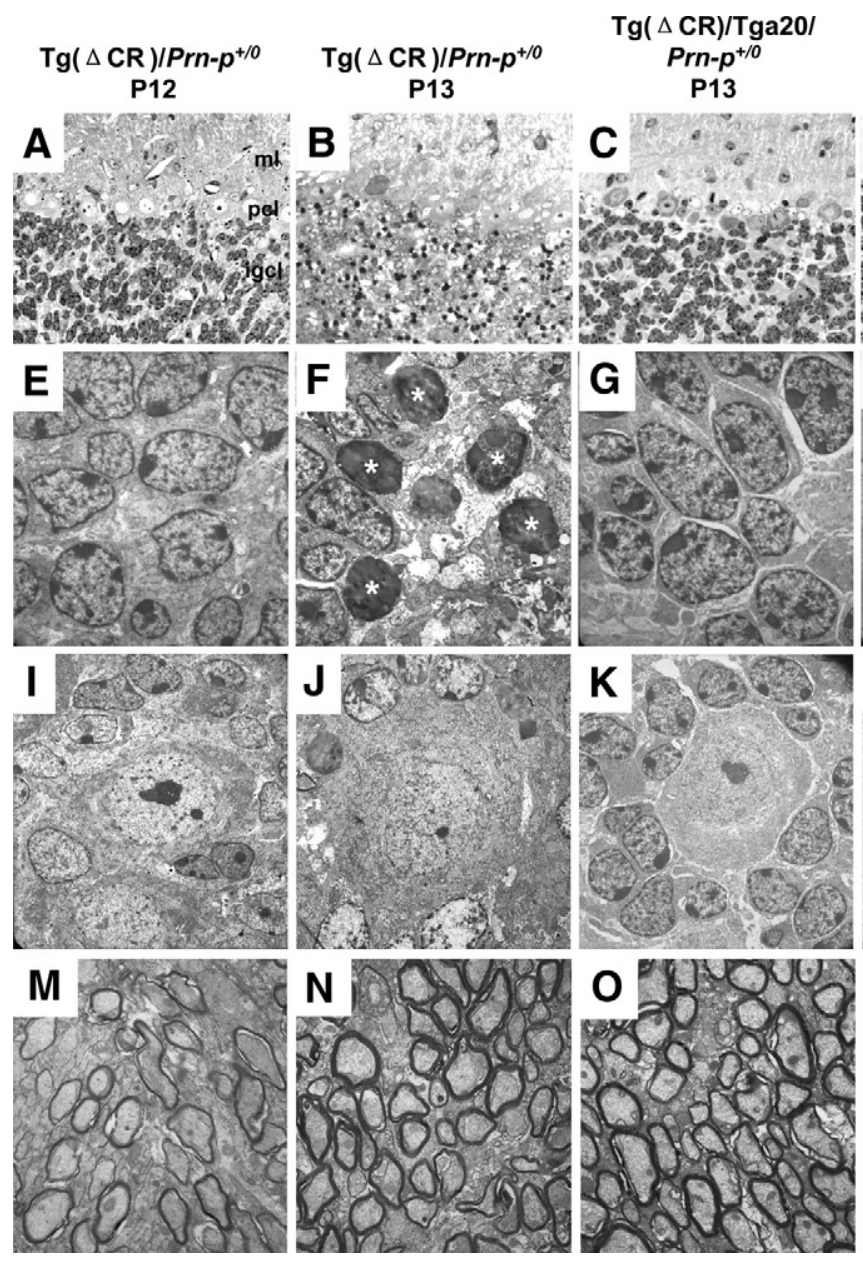

trol mice, suggesting that autophagic vacuoles do not accumulate in the brains of the transgenic animals, as would be expected if autophagic cell death pathways were activated (data not shown). This conclusion is supported by our electron microscopic analysis (see below), in which we did not observe typical, double-membrane autophagosomes in dying granule neurons of $\mathrm{Tg}(\Delta \mathrm{CR})$ mice. Taken together, our results indicate that autophagic pathways do not contribute in a significant way to neuronal death in $\mathrm{Tg}(\Delta \mathrm{CR})$ mice.

\section{Degenerating CGNs in Tg( $\Delta C R) / P r n-p^{+/ 0}$ Mice Display a Unique Morphology}

Historically, characterization of cell death processes has relied heavily on morphological criteria derived from light and electron microscopy. ${ }^{26}$ Because our biochemical experiments suggested that neuronal death in $\mathrm{Tg}(\Delta \mathrm{CR})$ mice was neither apoptotic nor autophagic, we turned to an ultrastructural approach with the goal of further classifying the underlying mechanism.

We first analyzed the cerebella of postnatal $\operatorname{Tg}(\Delta \mathrm{CR}) /$ Prn- $p^{+/ O}$ mice to detect when the earliest morphological changes occur in granule neurons. These animals first show clinical symptoms at P12 and die at approximately P25. ${ }^{8}$ At the light microscopic level, we observed no
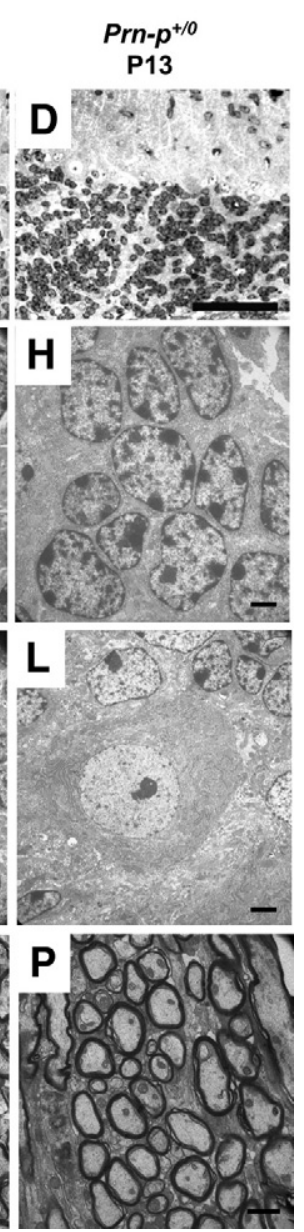

Figure 4. Rapid appearance of degenerating CGNs between $\mathrm{P} 12$ and $\mathrm{P} 13$ in $\operatorname{Tg}(\Delta \mathrm{CR}) / \mathrm{Prn}$ $p^{+/ O}$ mice. Cerebellar sections were prepared from $\operatorname{Tg}(\Delta \mathrm{CR}) / P r n-p^{+/ 0}$ mice at $\mathrm{P} 12(\mathbf{A}, \mathbf{E}, \mathbf{I}$, and $\mathbf{M})$ and $\mathrm{P} 13(\mathbf{B}, \mathbf{F}, \mathbf{J}$, and $\mathbf{N})$; and from $\operatorname{Tg}(\Delta \mathrm{CR})$ Tga20/Prn- ${ }^{+/ 0}(\mathbf{C}, \mathbf{G}, \mathbf{K}$, and $\mathbf{O})$ and $P r n-p^{+/ 0}$ mice $(\mathbf{D}, \mathbf{H}, \mathbf{L}$, and $\mathbf{P})$ at P13. A-D: Semithin plastic sections from each sample group were stained with methylene blue/azure II and evaluated by light microscopy. The molecular layer $(\mathrm{ml})$, Purkinje cell layer (pcl), and internal granule cell layer (igcl) are indicated in $\mathbf{A}$. Large numbers of pyknotic granule cells appear in the internal granule cell layer of $\operatorname{Tg}(\Delta \mathrm{CR}) / \mathrm{Prn}-\mathrm{p}^{+/ 0}$ mice at P13 (B), corresponding to the onset of clinical illness. ${ }^{8} \mathbf{E}-\mathbf{P}$ : Electron microscopic images of cerebellar architecture in $\operatorname{Tg}(\Delta \mathrm{CR})$ mice. Representative images of the internal granule cell layer (E-H), Purkinje cell layer (I-L), and cerebellar white matter $(\mathbf{M}-\mathbf{P})$ are shown. Asterisks in $\mathbf{F}$ indicate degenerating CGNs. Scale bars: $250 \mu \mathrm{m}(\mathbf{A}-\mathbf{D}) ; 1.7 \mu \mathrm{m}(\mathbf{E}-\mathbf{H}) ; 2.5 \mu \mathrm{m}$ (I-L); and $1.1 \mu \mathrm{m}(\mathbf{M}-\mathbf{P})$. discernable changes in $\mathrm{Tg}(\Delta \mathrm{CR}) / \operatorname{Prn}_{-} p^{+/ 0}$ cerebellum through P12 (Figure 4A). By electron microscopy, most granule neurons at P12 possessed normal ultrastructural characteristics (Figure 4E). However, a small proportion of granule neurons in mice at this stage had begun to exhibit signs of cellular distress in the nucleus and cytoplasm. Affected CGNs displayed abnormal nuclei that contained small, irregularly shaped chromatin clumps within a pyknotic nuclear matrix (Figure 5, A-C). Cytoplasmic abnormalities were also present in some cells, including condensation of the cytoplasmic matrix, mitochondrial swelling (asterisks in Figure 5, A-D), dilation of the Golgi cisternae (arrows in Figure 5, A, B, and D), and ribosomal clustering (circles in Figure 5D).

Remarkably, only 24 hours later (at P13), there was a dramatic accumulation of pyknotic granule neurons in the $\mathrm{Tg}(\Delta \mathrm{CR}) / \mathrm{Prn} \mathrm{p}^{+/ 0}$ cerebellum that was observable by light microscopy (Figure 4B). Electron microscopic analysis of these cells revealed a unique morphology. The most striking ultrastructural feature was in the nucleus, where there was a prominent increase in electron density throughout the entire nuclear matrix (Figure 4F). Chromatin was condensed into disorganized, interconnected clumps that filled the entire nucleus but that did not coalesce into chromatin masses characteristic of apoptosis. Of note, the integrity of the nuclear envelope was 

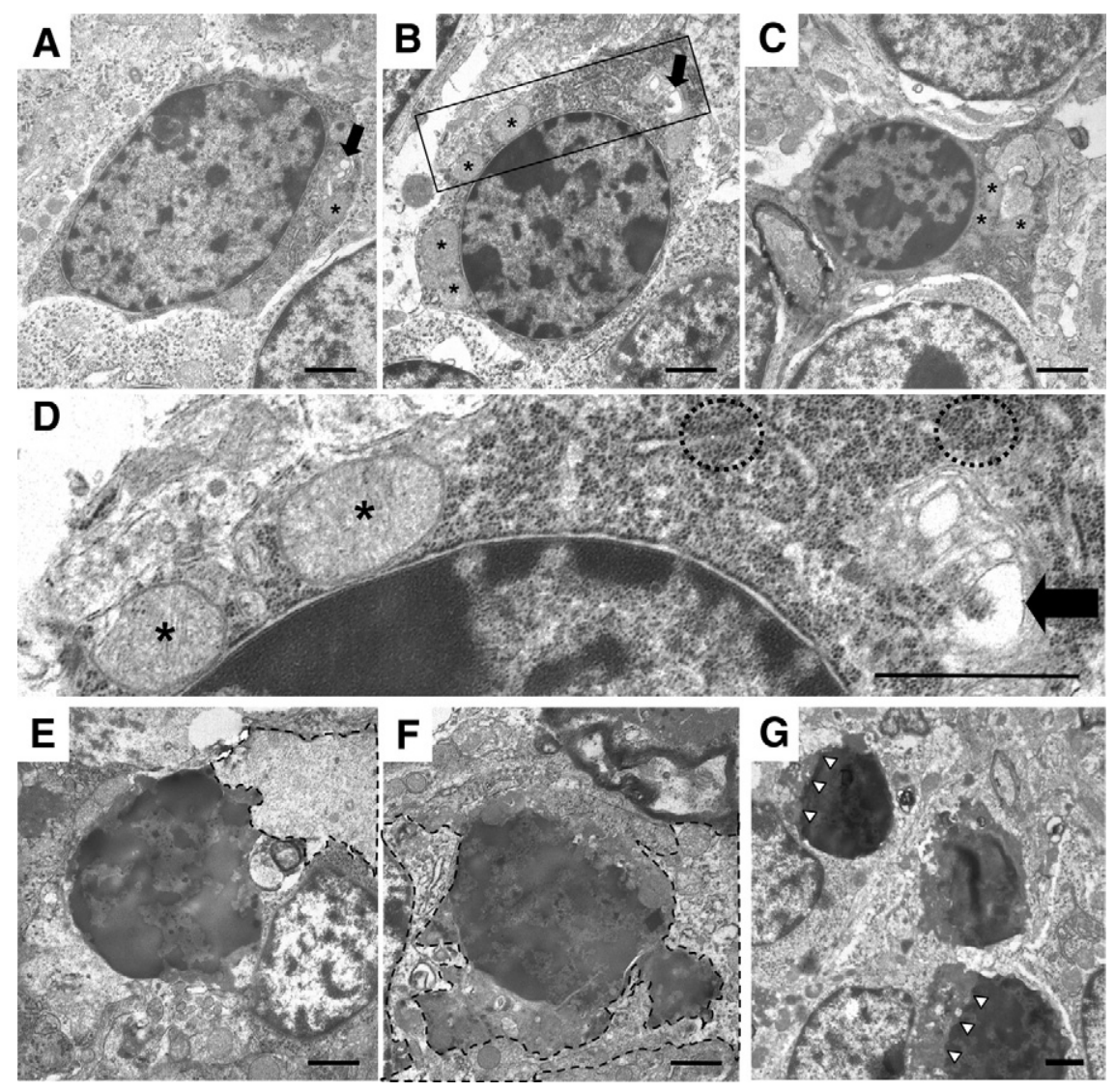

Figure 5. Distinctive ultrastructural changes displayed by CGNs in $\mathrm{Tg}(\Delta \mathrm{CR}) / P r n-p^{+/ O}$ mice Electron microscopic images of CGNs in $\operatorname{Tg}(\Delta \mathrm{CR}) /$ Prn $^{-p^{+/ 0}}$ mice at P12 (A-D), P13 (E and $\mathbf{F})$, and P20 (G). D shows a higher magnification of the area within the box in B. At P12, dying granule cells exhibit nuclear abnormalities such as matrix condensation and small, irregular dispersed chromatin clumps (A-D). Other cellular changes include cytoplasmic matrix condensation, swelling of mitochondria (asterisks), clustering of ribosomes (dashed circles), and dilation of the Golgi apparatus (black arrows) At P13, cells have continued to condense (E and F), with active phagocytosis occurring. Dashed lines outline phagocytic processes from adjacent glial cells. At P20, CGNs display similar morphological abnormalities. G: Whereas cell bodies become progressively shrunken, the nuclear membrane remains intact (white arrowheads). Scale bars in all panels: $1.1 \mu \mathrm{m}$. largely preserved until late in the degeneration process, with the condensed chromatin in the nucleus clearly demarcated from the cytoplasmic compartment (Figure 5G, arrowheads). Cell bodies of dying CGNs became highly shrunken, and condensation of the nuclear and cytoplasmic matrices (Figure 5, E-G) made it difficult to discern any further changes in the substructure of these compartments. By P13, many dying CGNs were already being cleared by phagocytosis (dashed lines in Figure 5, E and F), although many degenerated CGNs could still be observed at late stages of illness (P20; Figure 5G). We did not observe double-membrane autophagosomes indicative of autophagy during any stage of CGN death in $\mathrm{Tg}(\Delta \mathrm{CR}) / \operatorname{Prn}-p^{+/ 0}$ mice.

The distinctive CGN pathology described here was observed exclusively in cells residing in the internal granule cell layer. CGNs in the external granule layer did not undergo degenerative changes up to P16, by which time this layer has largely disappeared ${ }^{27}$ (data not shown). In addition, we did not observe any abnormalities in Purkinje cell bodies (Figure 4, I and J), white matter (Figure 4, M and $\mathrm{N}$ ), or the molecular layer of the cerebellum (data not shown) of $\mathrm{Tg}(\Delta \mathrm{CR}) / \mathrm{Prn}-p^{+/ O}$ mice. No degenerating neurons or other pathological changes were observed in the cerebella of rescued $\mathrm{Tg}(\Delta \mathrm{CR})$ mice overexpressing wildtype $\operatorname{PrP}\left(\mathrm{Tg}(\Delta \mathrm{CR}) / \mathrm{Tga} 20 / \mathrm{Prn}-\mathrm{p}^{+/ O}\right)$ or nontransgenic littermates $\left(P r n-p^{+/ O}\right)$ at either P13 (Figure 4, C, D, G, H, K, $L, O$, and $P$ ) or P20 (data not shown).

\section{Delaying Clinical Illness in Tg( $\Delta C R)$ Mice Does Not Alter the Morphology of Dying CGNs but Reveals Axonal Pathology}

The rapid appearance of degenerating CGNs between postnatal days 12 and 13 in $\mathrm{Tg}(\Delta \mathrm{CR}) / \mathrm{Prn}-p^{+/ 0}$ mice, coinciding with the onset of clinical illness, ${ }^{8}$ raised the question of whether the cell death process was related to a specific developmental event occurring at this age. To address this question, we examined the cerebella of $\mathrm{Tg}(\Delta \mathrm{CR})$ mice in which the onset of symptoms was delayed due to the presence of two copies of the wild-type PrP allele. $\mathrm{Tg}(\Delta \mathrm{CR}) / \mathrm{Prn}-\mathrm{p}^{+/+}$mice become symptomatic at P17, with terminal illness occurring at P48. ${ }^{8}$

In P26 Tg( $\Delta \mathrm{CR}) / \operatorname{Prn}_{-} \mathrm{p}^{+/+}$mice, we observed that $\mathrm{dy}$ ing CGNs possessed nuclear changes that were identical to those seen in P13 $\mathrm{Tg}(\Delta \mathrm{CR}) / \mathrm{Prn}-\mathrm{p}^{+/ 0}$ mice. In some cases, what appeared to be several different stages of granule neuron degeneration were apparent in the same section (Figure 6, A and G). Cells at an early stage possessed cytoplasmic condensation with mild chromatin clumping, whereas those at intermediate and advanced stages showed increased atrophy and chromatin condensation throughout the entire nucleus. Occasionally, we observed dying granule neurons in which the chromatin appeared to be herniating from a nucleus that contained patchy accumulations of condensed chroma- 

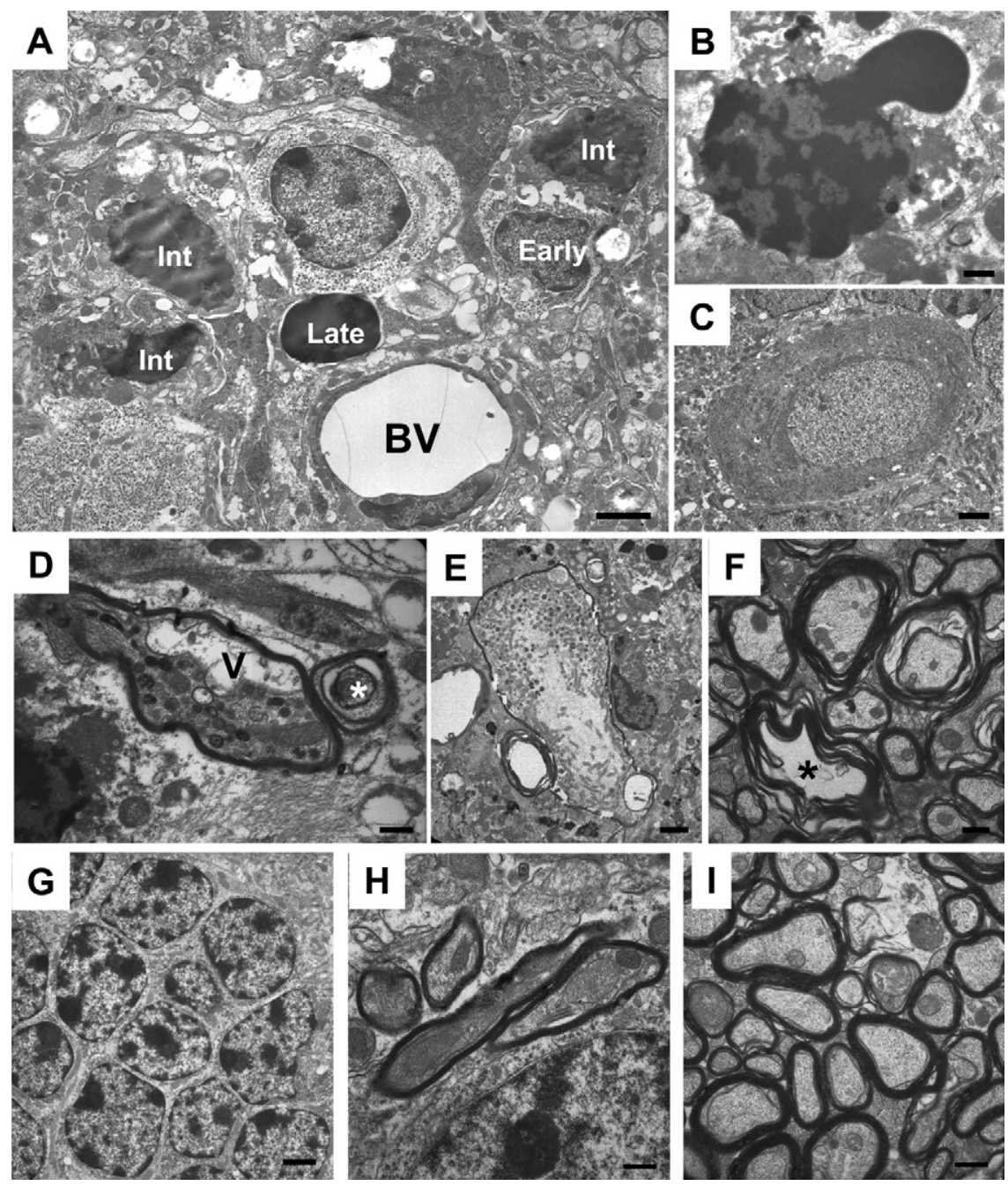

Figure 6. Delaying illness in $\operatorname{Tg}(\Delta \mathrm{CR})$ mice does not alter CGN morphology but reveals axonal pathology. A-F: Cerebellar sections from P26 $\operatorname{Tg}(\Delta \mathrm{CR}) /$ Prn $-p^{+/+}$mice. A: Degenerating granule cells exhibit heterogeneous condensation of the nucleus in the absence of discrete chromatin spheroids, as seen in $\mathrm{P} 13 \operatorname{Tg}(\Delta \mathrm{CR})$ Prn- $p^{+/ 0}$ mice (Figures 4 and 5). Different stages of degeneration were present simultaneously, as indicated by "early," "int" (intermediate), and "late" labels. BV, blood vessel. B: Degenerating CGN with herniation of chromatin from the nucleus. C: Normal Purkinje cell. D and E: Myelinated Purkinje cell axons within the internal granule cell layer display dystrophic changes, including swelling and axoplasmic organelle accumulation. A swollen, vacuolated axon is indicated by the "V." Concentric intraaxoplasmic rings were also observed (asterisk). F: Small and medium caliber axons in the cerebellar white matter also display defects, such as a lack of axoplasm (asterisk). Granule cells $(\mathbf{G})$, presumptive Purkinje cell axons $(\mathbf{H})$, and cerebellar white matter axons (I) from a P26 Prn- $\mathrm{p}^{+/+}$control mouse appear normal. Scale bars: $1.7 \mu \mathrm{m}(\mathbf{A}, \mathbf{E}$, and $\mathbf{G}) ; 0.6 \mu \mathrm{m}(\mathbf{B}, \mathbf{D}, \mathbf{F}, \mathbf{H}$, and I); $2.5 \mu \mathrm{m}(\mathbf{C})$. tin (Figure 6B). However, most of the nuclear membrane remained intact. No pathology was observed in Purkinje cell perikarya (Figure 6, $\mathrm{C}$ and $\mathrm{H}$ ). These results demonstrate that increased expression of wild-type PrP in $\mathrm{Tg}(\Delta \mathrm{CR}) / \mathrm{Prn} \mathrm{p}^{+/+}$mice delays the onset of clinical symptoms without altering the morphological characteristics of CGN death. We thus conclude that the cell death pathways being activated are not exclusively dependent on a specific developmental event occurring in the cerebellum at P12/P13.

An axonal pathology emerged in $\mathrm{Tg}(\Delta \mathrm{CR})$ mice on the Prn- $p^{+/+}$background that was not apparent in mice on the Prn- $p^{+/ O}$ background, possibly reflecting the more protracted disease course in the former animals (Figure 6, D-F). We observed large caliber, myelinated axons, most probably from Purkinje cells, within the granule cell layer and underlying white matter that were dystrophic and swollen with accumulations of vacuoles and organelles (Figure 6, D, E, and I). Occasionally, these axons displayed concentric, intraaxoplasmic rings (asterisk in Figure 6D). We also noted pathological changes, such as degenerating myelin sheaths and lack of axoplasm, in small and medium caliber axons within the cerebellar white matter (Figure 6F).

\section{Mice Expressing Another PrP Deletion Display CGN and Axonal Pathology Similar to that Seen in $\mathrm{Tg}(\triangle C R)$ Mice}

$\operatorname{Tg}(\mathrm{F} 35)$ mice, which express a PrP molecule carrying a larger deletion ( $\Delta 32-134)$, display a neurodegenerative phenotype that is also suppressed by coexpression of wild-type PrP. ${ }^{6}$ Although the phenotype of $\mathrm{Tg}(\mathrm{F} 35)$ mice is less severe than that of $\mathrm{Tg}(\Delta \mathrm{CR})$ mice and requires lower levels of wild-type PrP for rescue, we wondered whether the morphological characteristics of neuronal degeneration were similar in the two kinds of mice. Electron microscopic analysis of symptomatic Tg(F35)/Prn-p/O mice at P32 (Figure 7A) and P65 (Figure 7B) revealed that degenerating CGNs displayed morphological features that were similar to those observed in $\mathrm{Tg}(\Delta \mathrm{CR})$ mice. Degenerating CGNs exhibited patchy chromatin condensation throughout the nucleus, darkened cytoplasm, and maintenance of the nuclear membrane. Again, we did not observe discrete chromatin masses indicative of neuronal apoptosis. As in $\mathrm{Tg}(\Delta \mathrm{CR})$ mice, Purkinje cell bodies appeared healthy in $\mathrm{Tg}(\mathrm{F} 35)$ mice (Figure 7C). 

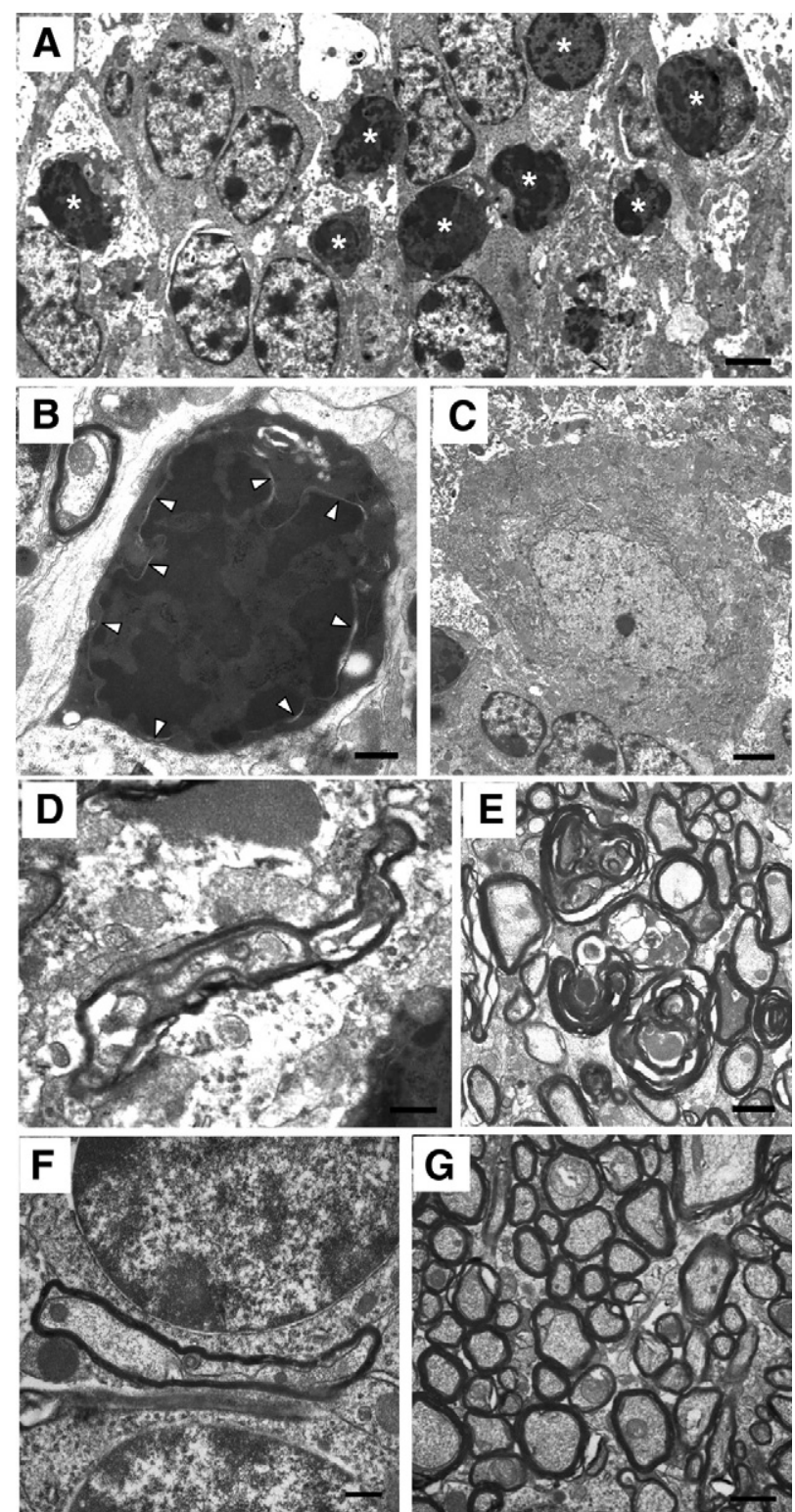

Figure 7. PrP $\Delta 32-134$ induces nonapoptotic death of CGNs as well as axonal pathology. Ultrastructural analysis of the cerebella of clinically ill $\operatorname{Tg}(\mathrm{F} 35) / P r n-p^{O / O}$ mice at P32 (A and C-E) and P65 (B). A: Clusters of degenerating granule cells (asterisks) exhibit morphological characteristics similar to those seen in $\operatorname{Tg}(\Delta \mathrm{CR})$ mice, including cellular shrinkage, darkening of the cytoplasmic matrix, and condensation of chromatin into interconnected clumps throughout the nucleus, with preservation of the nuclear membrane. B: Degenerating CGN displaying markedly condensed cytoplasm and accumulation of chromatin clumps but with maintenance of an intact nuclear membrane (arrowheads). C: Purkinje cell bodies remain normal. D: Swollen and dystrophic Purkinje cell axons in the granule cell layer contained vacuolated axoplasm. E: Axons in the cerebellar white matter display disintegrating myelin sheaths. Purkinje cell axons (F) and cerebellar white matter $(\mathbf{G})$ of a P30 Prn- $p^{0 / 0}$ control mouse are normal. Scale bars: $2.5 \mu \mathrm{m}(\mathbf{A}$ and $\mathbf{C}) ; 0.6 \mu \mathrm{m}(\mathbf{B}, \mathbf{D}$, and $\mathbf{F}) ; 1.1 \mu \mathrm{m}(\mathbf{E}$ and $\mathbf{G})$.

In addition, $\mathrm{Tg}(\mathrm{F} 35) / \mathrm{Prn}-\mathrm{p}^{\text {O/O }}$ mice showed extensive axonal pathology similar to that observed in $\mathrm{Tg}(\Delta \mathrm{CR})$ mice. Purkinje cell axons within the granule cell layer exhibited swelling, with condensation and vacuolation of the axoplasm (Figure 7D), and axons in the cerebellar white matter displayed dystrophic myelin sheaths (Figure 7E). Healthy, age-matched, Prn- $p^{O / O}$ control mice showed normal axonal morphology (Figure 7, F and G).

\section{Comparison with Apoptotic Neurons in Lurcher Mice}

To clearly distinguish the morphological features of neuronal death in $\mathrm{Tg}(\Delta \mathrm{CR})$ and $\mathrm{Tg}(\mathrm{F} 35)$ mice from those of classical apoptosis, we performed an electron microscopic examination of the cerebella of mice harboring the Lurcher mutation. By electron microscopy, CGNs of Lurcher mice (Figure 8, D-F) showed classical morphological features of apoptosis that were clearly distinct from those seen in $\mathrm{Tg}(\Delta \mathrm{CR})$ mice (Figure 8, $\mathrm{A}$ and $\mathrm{B}$ ) and $\mathrm{Tg}$ (F35) mice (Figure 8C). Differences were apparent in both the nuclear and cytoplasmic compartments. In the earliest stages, the chromatin of neurons in Lurcher mice became highly condensed and assumed a characteristic margination pattern along the edge of the nuclear envelope (Figure 8, D and E). In later stages, the chromatin condensed into discrete, osmiophilic spheres (Figure $8 \mathrm{~F})$. In contrast, granule neurons from $\mathrm{Tg}(\Delta \mathrm{CR})$ and $\mathrm{Tg}(\mathrm{F} 35)$ mice never showed chromatin margination, and the condensed chromatin formed irregular clumps in the nucleoplasm that never coalesced into discrete, round masses (Figure 8, A-C). Neurons in Lurcher mice showed disruption of mitochondrial integrity early in the apoptotic process (insets, Figure 8, D and E), whereas mitochondria in $\mathrm{Tg}(\Delta \mathrm{CR})$ neurons became swollen, but their outer membranes remained intact (Figure 5D). Finally, CGNs from $\mathrm{Tg}(\Delta \mathrm{CR})$ and $\mathrm{Tg}(\mathrm{F} 35)$ mice exhibited a characteristic condensation and compaction of the cytoplasmic matrix (Figure 8, A-C) that was not seen in apoptotic neurons from Lurcher mice until late in the cell death process (Figure 8, D-F). Degenerating neurons in Lurcher mice, like those in $\mathrm{Tg}(\Delta \mathrm{CR})$ mice, were sometimes seen to be in close proximity to invading astrocytic processes (data not shown), suggestive of active phagocytosis.

\section{Discussion}

The present study was undertaken with the objective of characterizing, using both biochemical assays as well as light and electron microscopy, the cell death pathways responsible for degeneration of CGNs in $\mathrm{Tg}(\Delta \mathrm{CR})$ mice. Our results indicate that forms of PrP lacking the conserved central region induce neuronal death by a caspase-independent mechanism that is distinct from both apoptosis and autophagy. This process bears striking similarities to neuronal death triggered by excitotoxic stress. These observations have important implications for understanding the neurotoxic pathways activated by alterations in cell surface $\operatorname{PrP}$, and they suggest testable hypotheses for investigating the molecular components of these pathways.

\section{Neuronal Death in $\mathrm{Tg}(\Delta \mathrm{CR})$ Mice Lacks Features of Apoptosis and Autophagy}

Classical apoptotic pathways are regulated through the concerted action of $\mathrm{Bcl}-2$ family members and the caspase family of cysteine proteases. ${ }^{15}$ In the intrinsic 

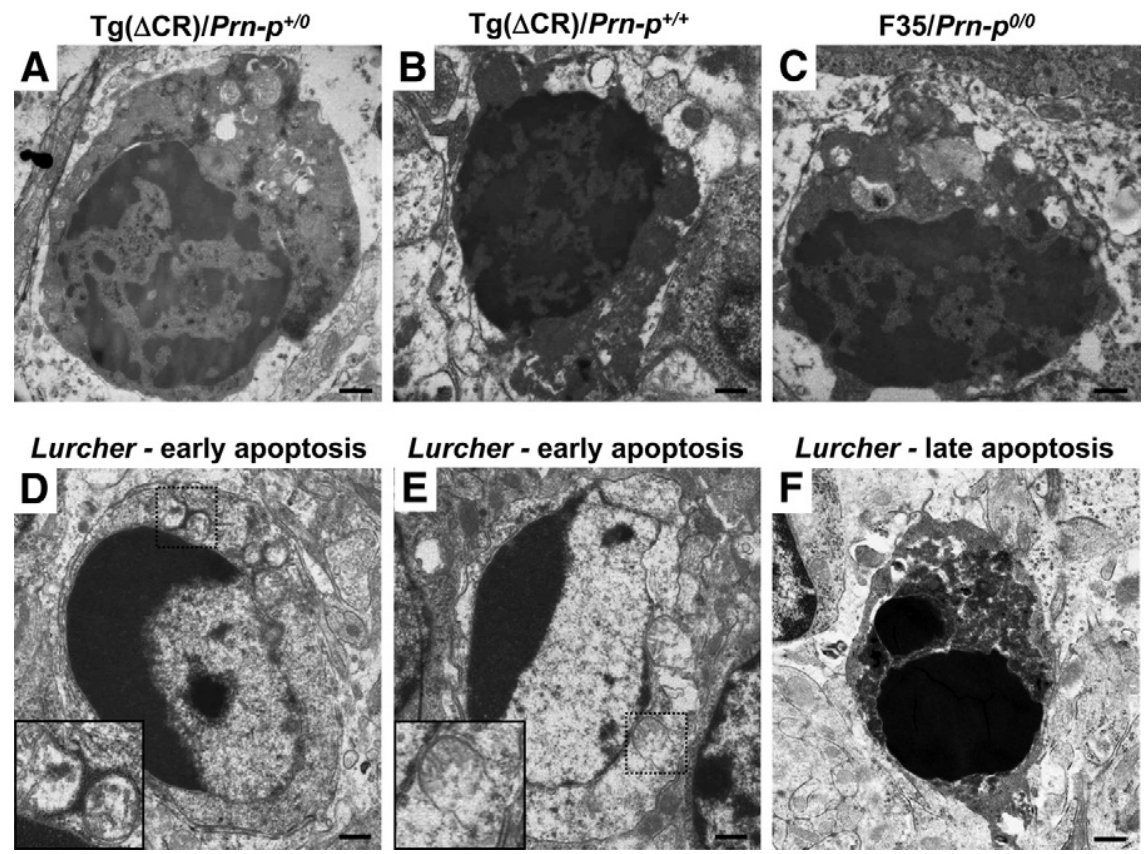

Figure 8. Mice expressing either of two deleted forms of PrP show a common type of neuronal death that is morphologically distinguishable from apoptosis. Representative images of degenerating CGNs are shown from a P12 $\operatorname{Tg}(\Delta \mathrm{CR})$

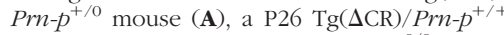
mouse (B), and a P32 $\mathrm{Tg}(\mathrm{F} 35) / P r n-p^{0 / 0}$ mouse (C). In each case, chromatin is condensed into disorganized, interconnected clumps that filled the nucleus but that never coalesce into discrete chromatin spheroids. There is no evidence of nuclear membrane fragmentation at these stages. The cytoplasm stains darkly and is depleted of organelles. D-F show representative images of CGNs undergoing apoptosis in P15 Lurcher $\left(\right.$ Grid $\left.2^{L C /+}\right)$ mice. D and E: Early stage of apoptotic cell death showing classical chromatin margination, as well as disruption of mitochondrial integrity (insets, which show boxed areas at higher magnification). The cytoplasm maintains a norma appearance. F: Late-stage, apoptotic CGN possessing two discrete, darkly staining chromatin masses. Scale bars: $0.6 \mu \mathrm{m}(\mathbf{A}-\mathbf{F})$. (mitochondrial) pathway, activation of proapoptotic family members by upstream BH3-only proteins results in permeabilization of the outer mitochondrial membrane, allowing release of cytochrome $c$, with subsequent activation of caspases 9 and $3 .^{28}$ In the extrinsic pathway, activation of cell surface death receptors by ligand binding leads directly to cleavage of caspase-8, which in turns cleaves caspase-3. ${ }^{29}$

In a previous report, ${ }^{30}$ we demonstrated that CGN death in $\mathrm{Tg}(\Delta \mathrm{CR}) / \mathrm{Prn}-\mathrm{p}^{+/ O}$ mice is not affected by genetic deletion of Bax, the sole proapoptotic, multidomain $\mathrm{Bcl}-2$ family member expressed in these neurons, ${ }^{31}$ suggesting lack of involvement of the intrinsic pathway. Here, we did not detect activation of caspase-3 in $\mathrm{Tg}(\Delta \mathrm{CR})$ / Prn- $p^{+/ O}$ cerebella, based on enzymatic activity assays, Western blotting, and immunofluorescence staining for the cleaved form of the enzyme. In addition, we did not observe increased activity of caspase-8, confirming lack of reliance on the extrinsic pathway. Taken together, these data indicate that CGN death in $\mathrm{Tg}(\Delta \mathrm{CR})$ mice occurs independently of both caspases and Bax, strongly suggesting involvement of a nonapoptotic process.

Using electron microscopy, we found that the ultrastructural appearance of degenerating CGNs from $\mathrm{Tg}(\Delta \mathrm{CR})$ mice was clearly distinct from that of neurons undergoing classical apoptosis (as exemplified by CGNs in Lurcher mice). One prominent characteristic of apoptotic neurons is the presence of highly condensed chromatin, visible either as crescent-shaped marginations early in the apoptotic program, or densely staining, spheroid masses at later stages. ${ }^{32}$ In contrast, in CGNs from $\mathrm{Tg}(\Delta \mathrm{CR})$ mice, the nuclear matrix became condensed early in the death process and contained small interconnected chromatin clumps that filled the entire nucleus but that never coalesced into discrete, highly osmiophilic masses. In addition, the integrity of the nuclear envelope was largely maintained in CGNs from $\mathrm{Tg}(\Delta \mathrm{CR})$ mice, with occasional herniation of chromatin through an otherwise intact membrane. This contrasts with classical apoptosis, where the nuclear envelope disintegrates entirely. ${ }^{26,32,33}$ Finally, during apoptosis most morphological abnormalities are confined initially to the nucleus, with cells maintaining a normal cytoplasmic appearance until late in the death process. However, CGNs from $\mathrm{Tg}(\Delta \mathrm{CR})$ mice displayed a dramatic condensation of the cytoplasmic matrix from a very early stage. Accompanying this change was marked swelling of mitochondria and the Golgi complex, in contrast to the disruption of the outer mitochondrial membrane that is characteristic of neuronal apoptosis. ${ }^{32,34}$

Autophagy is a process by which intracellular organelles and regions of cytoplasm are engulfed into autophagosomes, within which the components are degraded after fusion with lysosomes. ${ }^{35}$ Several observations suggest that neuronal death in $\mathrm{Tg}(\Delta \mathrm{CR})$ mice is nonautophagic. First, our electron microscopic analysis did not reveal typical, double-membrane autophagosomes in the cytoplasm of degenerating CGNs. Second, we did not detect accumulation of LC3-II, a marker of autophagosomes, by Western blotting. Finally, we did not observe a change in the subcellular distribution of LC3 immunoreactivity that typically occurs when autophagosomes accumulate in dying cells.

We show here that degenerating CGNs from Tg(F35) mice exhibit an ultrastructure similar to that observed in $\mathrm{Tg}(\Delta \mathrm{CR})$ mice. Thus, several forms of PrP with deletions spanning the central region ${ }^{10}$ are likely to induce neuronal death via a common, nonapoptotic mechanism. The same mechanism may also be activated by Doppel (Dpl), a $\operatorname{PrP}$ paralog structurally similar to $\operatorname{PrP}(\Delta N)$ and whose neurotoxicity is reversible by introduction of wild-type PrP. ${ }^{36,37}$ In our studies, neuronal death in Dpl-expressing 
mice is Bax independent ${ }^{38}$ and lacks ultrastructural features of apoptosis (our unpublished data).

\section{Is Neuronal Death in $\operatorname{Tg}(\triangle C R)$ Mice Necrotic?}

Forms of cell death that are nonapoptotic and nonautophagic are often categorized as "necrotic." 39 Necrotic cells typically exhibit pathology primarily in the cytoplasm, most notably swelling of intracellular organelles leading eventually to cellular lysis. ${ }^{40}$ In contrast, the most prominent morphological changes observed in $\mathrm{Tg}(\Delta \mathrm{CR})$ neurons occurred in the nucleus and were accompanied by extensive DNA fragmentation as revealed by TUNEL. Although we did note swelling of mitochondria and Golgi at an early stage, these alterations occurred concomitant with prominent chromatin condensation. Degenerating CGNs did not appear to lyse, and dying cells were phagocytosed by neighboring cells, possibly microglia or astrocytes. Although not definitive, our morphological data argue against a classical necrotic mechanism in $\mathrm{Tg}(\Delta \mathrm{CR})$ neurons.

\section{Similarities to Excitotoxic Death}

A nonapoptotic cell death mechanism has recently been described that exhibits many of the morphological and biochemical features seen in $\mathrm{Tg}(\Delta \mathrm{CR})$ neurons, including mild nuclear condensation, nuclear membrane maintenance, extensive DNA fragmentation, and caspase independence..$^{21,41}$ This pathway requires the activity of two key proteins, PARP-1 and apoptosis-inducing factor. Although several kinds of cellular damage can activate the PARP/apoptosis-inducing factor pathway, a well-studied trigger is glutamate-induced excitotoxicity in neurons. ${ }^{42}$ Interestingly, $\operatorname{PrP}$ was recently found to attenuate activation of NMDA receptors through a direct interaction with the NR2D subunit of the receptor, thereby protecting neurons from glutamate-induced excitotoxicity. ${ }^{43}$ Taken together, these observations suggest that $\operatorname{PrP}(\triangle C R)$ toxicity may involve inappropriate activation of NMDA-type glutamate receptors, leading to an excitotoxic form of neuronal death dependent on PARP-1 and apoptosisinducing factor.

\section{Myelinated Axon Pathology}

In addition to death of granule neurons, we observed a prominent degeneration of myelinated axons in the cerebella of $\mathrm{Tg}(\Delta \mathrm{CR}) / P r n-p^{+/+}$mice. Damaged axons, most likely arising from Purkinje cells, were found in the granule cell layer and the cerebellar white matter. Abnormal axons were swollen and displayed accumulations of organelles and vacuolated axoplasm, features suggesting a possible blockage of axonal transport. ${ }^{44,45}$ Some axons also displayed degeneration of the myelin sheath.

Granule cell death and axonal degeneration followed distinct time courses in $\mathrm{Tg}(\triangle \mathrm{CR})$ mice. In this study, axonal pathology was absent in $\mathrm{P} 13 \mathrm{Tg}(\Delta \mathrm{CR}) / \mathrm{Prn}-p^{+/ 0}$ mice at the time CGN loss began but became apparent by P26 in $\mathrm{Tg}(\Delta \mathrm{CR}) / \mathrm{Prn}-\mathrm{p}^{+/+}$mice. Conversely, we previ- ously observed that axonal damage occurs without CGN degeneration in older $\mathrm{Tg}(\Delta \mathrm{CR})$ mice ( $\sim 400$ days of age) that overexpress wild-type PrP from the Tga20 transgene. ${ }^{8}$ There is evidence that CGN loss and axonal degeneration are also mechanistically separate in $\mathrm{Tg}(\mathrm{F} 35)$ mice. ${ }^{7}$ These dissociations between neuronal death and axonal pathology may reflect differences in how the toxic signal delivered by deleted forms of $\operatorname{PrP}$ is received in the neuronal soma versus the axon or in neurons versus oligodendrocytes.

\section{Additional Cell Death Pathways Engaged by Deleted PrP and Dpl}

Although the present results highlight a role for nonapoptotic mechanisms, several studies suggest that apoptotic pathways may also contribute to neuronal death induced by deleted PrP and Dpl. Genetic deletion of Bax, or transgenic overexpression of Bcl-2, partially (but not completely) alleviates neuronal death in both $\mathrm{Tg}(\mathrm{F} 35)$ mice ${ }^{30,46}$ and Dpl mice. ${ }^{47,48}$ These effects may reflect the more protracted time course of illness in these animals compared with $\mathrm{Tg}(\triangle \mathrm{CR})$ mice, which may provide an opportunity for engagement of additional cell death mechanisms.

\section{Implications for Prion Diseases}

Although $\operatorname{PrP}(\Delta C R)$ and $\operatorname{PrP}(\Delta N)$ are artificial molecules, the neurotoxic pathways they activate may be related to those engaged by pathogenic forms of PrP that accumulate during a natural prion disease. Like the deleted PrP molecules, $\operatorname{PrP}^{\mathrm{Sc}}$ and other disease-associated forms may act by subverting a normal function of $\operatorname{PrP}^{\mathrm{C}}$, possibly one related to protection from cellular stress. ${ }^{8,49}$ Consistent with the results reported here, several recent studies demonstrate that neuronal death in infectious prion diseases does not involve mitochondrially mediated apoptosis. . $^{50,51}$

Most current strategies proposed for treatment of human prion diseases rely on inhibiting the formation of $\mathrm{PrP}^{\mathrm{Sc}}$ or enhancing its clearance. ${ }^{52}$ Identification of the cell death pathways activated by pathogenic forms of PrP may allow design of a new class of therapeutics based on blocking prion-induced neurotoxic mechanisms rather than $\operatorname{PrPSc}^{\mathrm{Sc}}$ accumulation. Further characterization at a molecular level of the novel death pathway delineated in this paper could prove useful in pursuing this strategy.

\section{Acknowledgments}

We thank Cheryl Adles and Su Deng for mouse maintenance, genotyping, and tissue preparation. Caspase-3 controls were a gift from Tim West. We gratefully acknowledge Marilyn Levy for assistance with electron microscopy. Adriano Aguzzi provided Tg(F35) mice, and Charles Weissmann, Prn-p/o and Tga20 mice. We also thank Marie Hardwick for critical reading of the manuscript. 


\section{References}

1. Prusiner SB: Prion Biology and Diseases. Cold Spring Harbor, New York, Cold Spring Harbor Laboratory Press, 2004, p. 1050

2. Mallucci G, Dickinson A, Linehan J, Klohn PC, Brandner S, Collinge J: Depleting neuronal PrP in prion infection prevents disease and reverses spongiosis. Science 2003, 302:871-874

3. Chesebro B, Trifilo M, Race R, Meade-White K, Teng C, LaCasse R, Raymond L, Favara C, Baron G, Priola S, Caughey B, Masliah E, Oldstone M: Anchorless prion protein results in infectious amyloid disease without clinical scrapie. Science 2005, 308:1435-1439

4. Brandner S, Isenmann S, Raeber A, Fischer M, Sailer A, Kobayashi Y, Marino S, Weissmann C, Aguzzi A: Normal host prion protein necessary for scrapie-induced neurotoxicity. Nature 1996, 379:339-343

5. Rambold AS, Muller V, Ron U, Ben-Tal N, Winklhofer KF, Tatzelt J: Stress-protective signalling of prion protein is corrupted by scrapie prions. EMBO J 2008, 27:1974-1984

6. Shmerling D, Hegyi I, Fischer M, Blättler T, Brandner S, Götz J, Rülicke T, Flechsig E, Cozzio A, von Mering C, Hangartner C, Aguzzi A, Weissmann C: Expression of amino-terminally truncated PrP in the mouse leading to ataxia and specific cerebellar lesions. Cell 1998, 93:203-214

7. Radovanovic I, Braun N, Giger OT, Mertz K, Miele G, Prinz M, Navarro B, Aguzzi A: Truncated prion protein and Doppel are myelinotoxic in the absence of oligodendrocytic PrPC . J Neurosci 2005, 25:48794888

8. Li A, Christensen HM, Stewart LR, Roth KA, Chiesa R, Harris DA: Neonatal lethality in transgenic mice expressing prion protein with a deletion of residues 105-125. EMBO J 2007, 26:548-558

9. Christensen HM, Harris DA: A deleted prion protein that is neurotoxic in vivo is localized normally in cultured cells. J Neurochem 2009, 108:44-56

10. Baumann F, Tolnay M, Brabeck C, Pahnke J, Kloz U, Niemann HH, Heikenwalder M, Rülicke T, Bürkle A, Aguzzi A: Lethal recessive myelin toxicity of prion protein lacking its central domain. EMBO $J$ 2007, 26:538-547

11. Büeler H, Fischer M, Lang Y, Fluethmann H, Lipp H-P, DeArmond SJ, Prusiner SB, Aguet M, Weissmann C: Normal development and behavior of mice lacking the neuronal cell-surface PrP protein. Nature 1992, 356:577-582

12. Chiesa R, Piccardo P, Ghetti B, Harris DA: Neurological illness in transgenic mice expressing a prion protein with an insertional mutation.. Neuron 1998, 21:1339-1351

13. West T, Atzeva M, Holtzman DM: Caspase-3 deficiency during development increases vulnerability to hypoxic-ischemic injury through caspase-3-independent pathways. Neurobiol Dis 2006, 22:523-537

14. Young C, Roth KA, Klocke BJ, West T, Holtzman DM, Labruyere J, Qin YQ, Dikranian K, Olney JW: Role of caspase-3 in ethanol-induced developmental neurodegeneration. Neurobiol Dis 2005, 20:608-614

15. Hengartner MO: The biochemistry of apoptosis. Nature 2000, 407:770-776

16. Gill R, Soriano M, Blomgren K, Hagberg H, Wybrecht R, Miss MT, Hoefer S, Adam G, Niederhauser O, Kemp JA, Loetscher H: Role of caspase-3 activation in cerebral ischemia-induced neurodegeneration in adult and neonatal brain. $J$ Cereb Blood Flow Metab 2002, 22:420-430

17. Zhu C, Wang X, Xu F, Bahr BA, Shibata M, Uchiyama Y, Hagberg H, Blomgren $\mathrm{K}$ : The influence of age on apoptotic and other mechanisms of cell death after cerebral hypoxia-ischemia. Cell Death Differ 2005, 12:162-176

18. Soldani C, Scovassi Al: Poly(ADP-ribose) polymerase-1 cleavage during apoptosis: an update. Apoptosis 2002, 7:321-328

19. Selimi F, Vogel MW, Mariani J: Bax inactivation in Lurcher mutants rescues cerebellar granule cells but not Purkinje cells or inferior olivary neurons. J Neurosci 2000, 20:5339-5345

20. Slagsvold HH, Rosseland CM, Jacobs C, Khuong E, Kristoffersen N, Gaarder M, Fallgren AB, Huitfeldt HS, Paulsen RE: High molecular weight DNA fragments are processed by caspase sensitive or caspase independent pathways in cultures of cerebellar granule neurons. Brain Res 2003, 984:111-121

21. Susin SA, Daugas E, Ravagnan L, Samejima K, Zamzami N, Loeffler M, Costantini P, Ferri KF, Irinopoulou T, Prevost MC, Brothers G, Mak TW, Penninger J, Earnshaw WC, Kroemer G: Two distinct pathways leading to nuclear apoptosis. J Exp Med 2000, 192:571-580
22. van Lookeren Campagne M, Lucassen PJ, Vermeulen JP, Balazs R: NMDA and kainate induce internucleosomal DNA cleavage associated with both apoptotic and necrotic cell death in the neonatal rat brain. Eur J Neurosci 1995, 7:1627-1640

23. Ribe EM, Serrano-Saiz E, Akpan N, Troy CM: Mechanisms of neuronal death in disease: defining the models and the players, Biochem $J$ 2008, 415:165-182

24. Kroemer G, Levine B: Autophagic cell death: the story of a misnomer Nat Rev Mol Cell Biol 2008, 9:1004-1010

25. Kabeya Y, Mizushima N, Ueno T, Yamamoto A, Kirisako T, Noda T, Kominami E, Ohsumi Y, Yoshimori T: LC3, a mammalian homologue of yeast Apg8p, is localized in autophagosome membranes after processing. EMBO J 2000, 19:5720-5728

26. Kerr JF, Wyllie AH, Currie AR: Apoptosis: a basic biological phenomenon with wide-ranging implications in tissue kinetics. $\mathrm{Br} J$ Cancer 1972, 26:239-257

27. Miale IL, Sidman RL: An autoradiographic analysis of histogenesis in the mouse cerebellum. Exp Neurol 1961, 4:277-296

28. Polster BM, Fiskum G: Mitochondrial mechanisms of neural cell apoptosis. J Neurochem 2004, 90:1281-1289

29. Curtin JF, Cotter TG: Live and let die: regulatory mechanisms in Fas-mediated apoptosis. Cell Signal 2003, 15:983-992

30. Li A, Barmada SJ, Roth KA, Harris DA: N-terminally deleted forms of the prion protein activate both Bax-dependent and Bax-independent neurotoxic pathways. J Neurosci 2007, 27:852-859

31. Uo T, Kinoshita Y, Morrison RS: Neurons exclusively express N-Bak, a $\mathrm{BH} 3$ domain-only Bak isoform that promotes neuronal apoptosis. J Biol Chem 2005, 280:9065-9073

32. Dikranian K, Ishimaru MJ, Tenkova T, Labruyere J, Qin YQ, Ikonomidou C, Olney JW: Apoptosis in the in vivo mammalian forebrain. Neurobiol Dis 2001, 8:359-379

33. Ishimaru MJ, Ikonomidou C, Tenkova TI, Der TC, Dikranian K, Sesma MA, Olney JW: Distinguishing excitotoxic from apoptotic neurodegeneration in the developing rat brain. J Comp Neurol 1999, 408:461-476

34. Dikranian K, Qin YQ, Labruyere J, Nemmers B, Olney JW: Ethanolinduced neuroapoptosis in the developing rodent cerebellum and related brain stem structures. Brain Res Dev Brain Res 2005, $155: 1-13$

35. Levine B, Kroemer G: Autophagy in the pathogenesis of disease. Cell 2008, 132:27-42

36. Moore RC, Mastrangelo P. Bouzamondo E, Heinrich C, Legname G Prusiner SB, Hood L, Westaway D, DeArmond SJ, Tremblay P: Doppel-induced cerebellar degeneration in transgenic mice, Proc Nat Acad Sci USA 2001, 98:15288-15293

37. Rossi D, Cozzio A, Flechsig E, Klein MA, Rülicke T, Aguzzi A, Weissmann C: Onset of ataxia and Purkinje cell loss in PrP null mice inversely correlated with Dpl level in brain. EMBO J 2001, 20:694-702

38. Dong J, Li A, Yamaguchi N, Sakaguchi S, Harris DA: Doppel induces degeneration of cerebellar Purkinje cells independently of Bax. Am J Pathol 2007, 171:599-607

39. Bredesen DE, Rao RV, Mehlen P: Cell death in the nervous system Nature 2006, 443:796-802

40. Van Cruchten S, Van Den Broeck W: Morphological and biochemical aspects of apoptosis, oncosis and necrosis. Anat Histol Embryol 2002, 31:214-223

41. Yu SW, Wang H, Poitras MF, Coombs C, Bowers WJ, Federoff HJ, Poirier GG, Dawson TM, Dawson VL: Mediation of poly(ADP-ribose) polymerase-1-dependent cell death by apoptosis-inducing factor. Science 2002, 297:259-263

42. Yu SW, Wang H, Dawson TM, Dawson VL: Poly(ADP-ribose) polymerase-1 and apoptosis inducing factor in neurotoxicity. Neurobiol Dis 2003, 14:303-317

43. Khosravani H, Zhang Y, Tsutsui S, Hameed S, Altier C, Hamid J, Chen L, Villemaire M, Ali Z, Jirik FR, Zamponi GW: Prion protein attenuates excitotoxicity by inhibiting NMDA receptors. J Cell Biol 2008, 181:551-565

44. Dikranian K, Cohen R, Mac Donald C, Pan Y, Brakefield D, Bayly P, Parsadanian A: Mild traumatic brain injury to the infant mouse causes robust white matter axonal degeneration which precedes apoptotic death of cortical and thalamic neurons. Exp Neurol 2008, 211:551560

45. Rodriguez-Paez AC, Brunschwig JP, Bramlett HM: Light and electron 
microscopic assessment of progressive atrophy following moderate traumatic brain injury in the rat. Acta Neuropathol 2005, 109:603-616

46. Nicolas O, Gavin R, Braun N, Urena JM, Fontana X, Soriano E, Aguzzi A, del Rio JA: Bcl-2 overexpression delays caspase-3 activation and rescues cerebellar degeneration in prion-deficient mice that overexpress amino-terminally truncated prion. FASEB J 2007, 21:3107-3117

47. Heitz S, Gautheron V, Lutz Y, Rodeau JL, Zanjani HS, Sugihara I, Bombarde G, Richard F, Fuchs JP, Vogel MW, Mariani J, Bailly Y: BCL-2 counteracts Doppel-induced apoptosis of prion-protein-deficient Purkinje cells in the Ngsk Prnp(0/0) mouse. Dev Neurobiol 2008, 68:332-348

48. Heitz S, Lutz Y, Rodeau JL, Zanjani H, Gautheron V, Bombarde G, Richard F, Fuchs JP, Vogel MW, Mariani J, Bailly Y: BAX contributes to Doppel-induced apoptosis of prion-protein-deficient Purkinje cells. Dev Neurobiol 2007, 67:670-686

49. Roucou X, LeBlanc AC: Cellular prion protein neuroprotective function: implications in prion diseases. J Mol Med 2005, 83:3-11

50. Coulpier M, Messiaen S, Hamel R, Fernandez de Marco M, Lilin T, Eloit M: Bax deletion does not protect neurons from BSE-induced death. Neurobiol Dis 2006, 23:603-611

51. Steele AD, King OD, Jackson WS, Hetz CA, Borkowski AW, Thielen P Wollmann R, Lindquist S: Diminishing apoptosis by deletion of Bax or overexpression of $\mathrm{Bcl}-2$ does not protect against infectious prion toxicity in vivo. J Neurosci 2007, 27:13022-13027

52. Trevitt CR, Collinge J: A systematic review of prion therapeutics in experimental models. Brain 2006, 129:2241-2265 